\title{
Genetic Inactivation of Melanin-Concentrating Hormone Receptor Subtype I (MCHRI) in Mice Exerts Anxiolytic-Like Behavioral Effects
}

\author{
Madhuri Roy*,', Nadia K David', Jean V Danao', Helene Baribault', Hui Tian' and Marco Giorgetti' \\ 'Amgen Inc., South San Francisco, CA, USA
}

\begin{abstract}
The biological effects of the melanin-concentrating hormone $(\mathrm{MCH})$ are mediated by the melanin concentrating hormone receptor I $(\mathrm{MCHRI})$ in mice. This receptor is enriched in brain areas that are involved in the modulation of mood and affect, suggesting that $\mathrm{MCH}$ dependent signaling may influence neurobiological mechanisms underlying fear and anxiety processes. To test this, we have generated mice lacking functional MCHRI and characterized phenotypic traits using a number of behavioral tests. Mice carrying a null mutation of the MCHRI gene display anxiolytic-like behavior across a battery different behavioral paradigms commonly used to assess fear and anxiety responses in rodents: open field, elevated plus maze, social interaction, and stress-induced hyperthermia. The brain serotonin $(5-H T)$ system is central to the control of mood- and anxiety-related processes. To examine the impact of MCHRI receptor deletion on 5-HT neurotransmission, we used in vivo microdialysis in freely moving knockout and wild-type mice. Baseline dialysate 5-HT levels were significantly lower in MCHRI knockout mice as compared with wild-type controls $(9.53 \pm 0.24 \mathrm{fmol}$ for wild types vs $6.91 \pm 0.36 \mathrm{fmol}$ for knockouts) in the prefrontal cortex (PFC), one of the main target structures of the serotonergic system and one that is highly associated with the control of emotional processes. Moreover, forced swim increased 5-HT efflux in the PFC of wild-type but not MCHRI knockout mice. In summary, we show that MCHRI can modulate stress- and anxiety-like behaviors and suggest that this may be due to changes in serotonergic transmission in forebrain regions.

Neuropsychopharmacology (2006) 3 I, I I2- 120. doi:I0. I038/sj.npp. I 300805; published online 29 June 2005
\end{abstract}

Keywords: $\mathrm{MCH}$; MCHRI; mouse; anxiety; knockout; serotonin

\section{INTRODUCTION}

Melanin-concentrating hormone $(\mathrm{MCH})$ is a cyclic neuropeptide, first isolated from the pituitary gland of salmon (Kawauchi et al, 1983), known to play a role in the control of food intake and energy balance in mammals. $\mathrm{MCH}-$ producing neurons in the rodent and primate brains are located in the lateral hypothalamus and zona incerta and extensively project to many brain areas (Bittencourt $e t a l$, 1992; Bittencourt et al, 1998), suggesting possible neuromodulatory functions for $\mathrm{MCH}$ (reviewed in Griffond and Baker, 2002). The biological effects of $\mathrm{MCH}$ are mediated by two G-protein-coupled receptors, melanin-concentrating hormone receptor subtype 1 (MCHR1) (SLC-1/GPR24) and melanin-concentrating hormone receptor subtype 2 (MCHR2), both of which belong to the rhodoposin-like

\footnotetext{
*Correspondence: Dr M Roy, Amgen Inc., I 120 Veterans Boulevard, South San Francisco, CA 94080, USA; Tel: + I 6502442297 , Fax: + I 650244 2400, E-mail: roym@stanfordalumni.org

Received 2 March 2005; revised 3 May 2005; accepted 4 May 2005 Online publication: 25 May 2005 at http://www.acnp.org/citations/ Npp052505050 143/default.pdf
}

G-protein-coupled receptor family of proteins. The MCHR1 subtype is expressed in most species examined, including rodents and humans, whereas functional MCHR2 receptors are expressed in humans and non-human primates and in a few other species, but not in rodents (Tan et al, 2002).

$\mathrm{MCH}$ signaling in the CNS has been most often described in the regulation of nutritional and energy homeostasis. Direct central administration of $\mathrm{MCH}$ stimulates food intake in rodents ( $\mathrm{Qu}$ et al, 1996), while the targeted disruption of the prepro- $\mathrm{MCH}$ gene in mice results in a lean phenotype, as a result of hypophagia and increased metabolic rate (Shimada et al, 1998). Likewise, receptor knockout mice are lean and are protected against dietinduced obesity (Chen et al, 2002; Marsh et al, 2002). Although the widespread innervations of $\mathrm{MCH}$-containing fibers and the expression of MCHR1 in brain areas such as the hippocampus, basolateral amygdala, and prefrontal cortex (PFC) (Saito et al, 2001) suggests potential involvement in the control of emotion and cognition, only a few reports have directly addressed this issue. Intracranial $\mathrm{MCH}$ administration has been shown to regulate response to novelty (Monzon et al, 2001; Kela et al, 2003) and learning and memory (Monzon et al, 1999). In the most suggestive 
study to date, acute systemic administration of a selective MCHR1 receptor antagonist to rodents elicited both anxiolytic- and antidepressant-like effects (Borowsky et al, 2002; Chaki et al, 2005).

Our study provides genetic evidence that the MCHR1 receptor subtype can mediate anxiety responses in rodents. Specifically, we have generated mice with a targeted null mutation of the MCHR1 receptor gene and tested them on a series of anxiety-related behavioral paradigms. We show that the lack of functional MCHR1 receptors in knockout mice results in an anxiolytic-like phenotype, observed consistently across a validated set of behavioral paradigms. In addition, we show that basal extracellular levels of serotoin (5-HT) are significantly lower in the PFC of MCHR1 knockout mice, a region of the brain critical for the regulation of emotion. Moreover, acute forced swim stress significantly increases 5-HT levels in the PFC of MCHR1 wild-type but not knockout mice. Taken together, our data show that functional inactivation of MCHR1 in mice results in an anxiolytic-like phenotype and induces changes in prefrontal cortical 5-HT transmission. These data suggest that the development of MCHR1 receptor antagonists may constitute a novel alternative strategy for the treatment of anxiety disorders.

\section{MATERIALS AND METHODS}

\section{Animals}

Generation of MCHR1-deficient mice. MCHR1-deficient mice were generated at Lexicon Genetics Inc. (The Woodlands, TX). Both exons 1 and 2 from the MCHR1 gene were substituted for a $5.3 \mathrm{~kb}$ neo cassette in the MCHR1 targeting vector, along with a total of approximately $8.5 \mathrm{~kb}$ of homology: $\sim 3.5 \mathrm{~kb} 5^{\prime}$ arm and $\sim 5 \mathrm{~kb} 3^{\prime}$ arm (Figure 1a). The targeting vector was introduced into embryonic stem (ES) cells derived from the $129 \mathrm{SvEvBrd}$ mouse strain. The integrity of the targeting events on the $5^{\prime}$ end was confirmed by Southern blot analysis of ES cells genomic DNA after digestion with BglII, using a probe located upstream of the arms of homology. The integrity of the targeting events on the $3^{\prime}$ end was confirmed after digestion of genomic DNA with KpnI, using a probe located downstream of the arms of homology. Targeted ES cell clones were injected into host blastocysts and resulting chimeric mice were bred to C57Bl/ $6 \mathrm{~J}$ albino mice to generate F1 heterozygotes. F1 heterozygotes were backcrossed to C57BL/6J mice for one generation. The resulting N1F1 heterozygotes were intercrossed to generate F2 homozygous mice.

The genotypes of wild-type and mutant mice were identified by triplex PCR analysis of genomic DNA from tail biopsies (Figure 1b). The wild-type-specific primer pair $(\mathrm{a} / \mathrm{b})$ produced a product of $490 \mathrm{bp}$ and the knockoutspecific primer $(\mathrm{c} / \mathrm{b})$ pair produced a product of $643 \mathrm{bp}$. Primers used were as follows: a-5'GACCTTTCGAAAA CGCTTGG; b-5'CTCACAGTAGAGCCCTAGC; c-5'GTGT GGCGGACCGCTATCA. To confirm the absence of MCHR1 mRNA in homozygous mutant mice, RT-PCR was performed on RNA prepared from whole brains of knockout and wild-type mice (Figure 1c). The following exonspanning primer pair was utilized to generate a $1012 \mathrm{bp}$
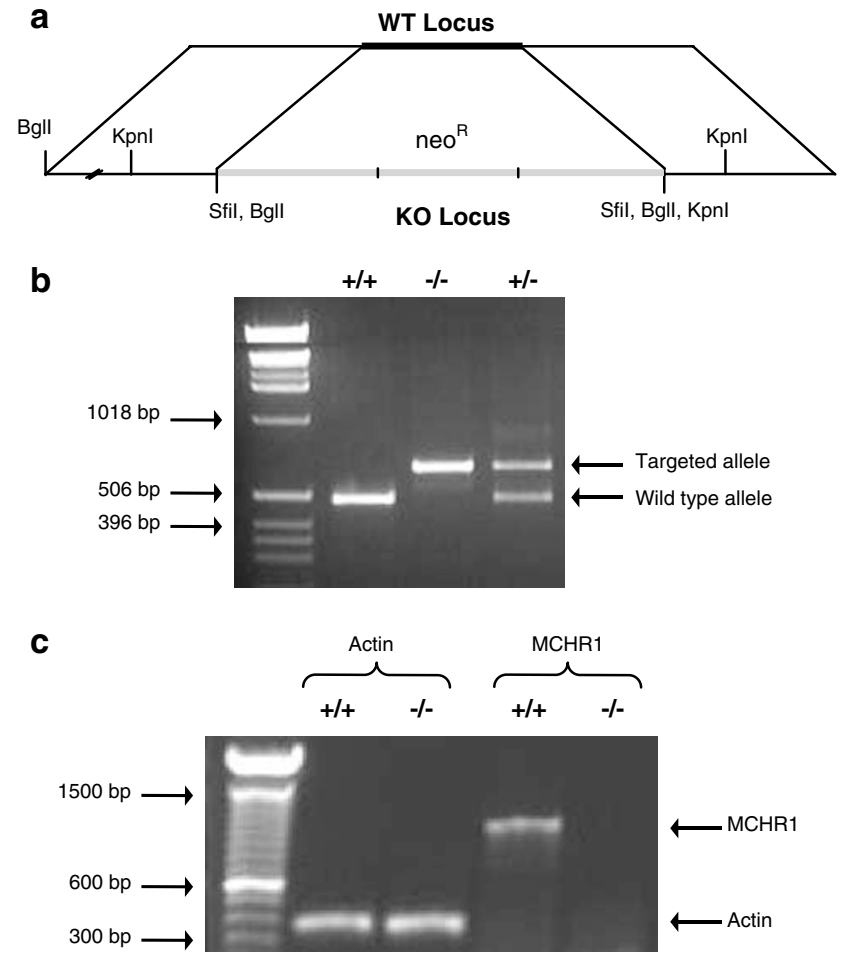

Figure I Generation of MCHRI-deficient mice. (a) Schematic map of the MCHRI wild-type locus and the inactivated MCHRI allele. Black box, open reading frame of the MCHRI gene; gray box, replacement cassette in mutated locus with neo ${ }^{R}$ (neomycin resistance) gene cassette. (b) Genotyping of animals. Mice were screened using PCR-based analysis of tail genomic DNA to identify wild-type, homozygous mutant, or heterozygous mutant animals. (c) Confirmation of MCHRI expression. RTPCR analysis of brain RNA from wild-type and knockout animals was performed to confirm the absence of MCHRI message in homozygous mice. $\beta$-Actin was used to control for RNA degradation and fidelity of PCR.

product: 5'CAACATCTCCGATGGCCAGGATAA (forward) and $5^{\prime}$ TGCCTTTGCTTTCTGTCCTCTCCTC (reverse).

\section{Housing}

Subjects were 3- to 10-month-old sexually naïve mice bred in our facility. The animal housing rooms were on a $12-\mathrm{h}$ light/dark cycle (lights on at 0600) with the temperature kept at $23-25^{\circ} \mathrm{C}$, and the humidity maintained at $40-60 \%$. Animals were housed in groups of 3-5, with ad libitum access to food and water and provided with environmental enrichment in the form of cotton nesting pads.

\section{Behavioral Phenotyping}

Testing. Knockout and wild-type littermates (also on a mixed background) were tested. Testing was performed in rooms dedicated to sensitive behavioral experiments and animals were brought to the rooms approximately $1 \mathrm{~h}$ before the testing began to allow for acclimation. All behavior testing was conducted in the second half of the light part of the light/dark cycle. There was a minimum of $72 \mathrm{~h}$ between behavioral tests, and the tests were carried out in the order listed below. All experiments were in compliance with approved protocols with oversight from 
the Institutional Animal Care and Use Committee. All behavioral paradigms were pharmacologically validated prior to testing mutant mice (data not shown).

Open field test. The open field test was conducted as described previously (Holmes et al, 2003). The open field consisted of a square arena $(40 \mathrm{~cm}$ length $\times 40 \mathrm{~cm}$ width $\times 38 \mathrm{~cm}$ depth) with clear Plexiglas floor and walls. Mice were placed in one corner of the open field and allowed to explore freely the arena during a 15-min test session. Both central and peripheral activities were measured using a computer-assisted activity system with appropriate software to facilitate data collection and analysis (San Diego Instruments, San Diego, CA). A total of 16 photobeams in each direction were positioned $2.5 \mathrm{~cm}$ apart, $2 \mathrm{~cm}$ above the floor, and center time was defined as time spent in the central $25 \times 25 \mathrm{~cm}$ area of the open field. Enhanced exploration of the unprotected central portion of a novel open field and reduced thigmotaxis (wall hugging) are behaviors most often correlated with reduced anxiety levels (Treit and Fundytus, 1988; Simon et al, 1994). In any given session, six test animals were run simultaneously in independent test chambers, with a pseudorandomization of placement of mutant and wild-type animals.

Elevated plus maze. The elevated plus maze was conducted as described previously (Lister, 1987; Holmes et al, 2003) and has been accordingly modified for use in our laboratory. Briefly, the apparatus was constructed of black Plexiglas and consisted of four arms $(30 \mathrm{~cm}$ length $\times 5 \mathrm{~cm}$ width): two closed arms with high, black walls $(30 \mathrm{~cm}$ high) and two open arms with a small raised lip $(0.5 \mathrm{~cm})$. All four arms were connected by a center platform $(5 \times 5 \mathrm{~cm})$. The maze was elevated to a height of $30 \mathrm{~cm}$ above the ground. Each mouse was placed on the center platform facing an open arm to initiate the test session of 5 min. A desk lamp placed above the apparatus provided even lighting. Increased exploration of the relatively aversive open arms is indicative of reduced anxiety-like behavior in this paradigm. Open/closed arm entries and time spent in the open/closed arms were scored by two trained observers. Arm entries were scored upon entry of the two front paws into the arm.

Social interaction test in a novel environment. To investigate another measure of anxiety, we tested individual mice in a social interaction paradigm, as described (Miyakawa et al, 2003) with modifications appropriate for our facility and laboratory setting. Group-housed male mice were tested individually in this test. The test subject was placed in a novel arena $(40 \times 40 \mathrm{~cm})$ with cage bedding following which a group-housed $\mathrm{C} 57 \mathrm{Bl} / 6$ male (intruder) was introduced into the arena. The two animals were allowed to explore freely for $10 \mathrm{~min}$ and the amount of time the test subject spent engaged in social investigation/ physical interaction (approaching, sniffing, mounting, grooming, fighting) was monitored. Cage bedding was mixed between animals so as to provide no guidance cues for the next test pair. No intruders were used more than once during any testing session. The number of contacts, total contact time, and mean duration time per contact were measured by two independent observers. Prior to the experiment, the pair of observers carried out a series of comparative validations, to ensure that there would be inter-rater reliability in the measures scored.

Stress-induced hyperthermia. The handling stress-induced paradigm was carried out as described previously (Van der Heyden et al, 1997; Bouwknecht and Paylor, 2002) with modifications for use in our facility. Animals were group housed and on the test day, the probe (Harvard Apparatus, Holliston, MA) was inserted into the rectum for about $2 \mathrm{~cm}$ and the temperature ( $T_{1}=$ basal temperature) was recorded. The mild stress of handling and temperature probe insertion into the rectum causes a hyperthermic response, which was recorded $10 \mathrm{~min}$ later $\left(T_{2}=\right.$ stressed temperature). The stress-induced hyperthermia was computed to be $\Delta T=T_{2}-T_{1}$.

\section{In Vivo Microdialysis}

Surgery. Prior to surgery, mice were anesthetized using ketamine $(100 \mathrm{mg} / \mathrm{kg}$ i.p.) and xylazine $(10 \mathrm{mg} / \mathrm{kg}$ i.p. $)$ and placed in a stereotaxic frame. A microdialysis guide cannula with a dummy (CMA/7 model; CMA, Chelmsford, MA) was implanted into the right $\mathrm{PFC}$ at the following coordinates relative to bregma: $\mathrm{AP}+2 \mathrm{~mm}$; $\mathrm{ML}-0.5 \mathrm{~mm}$; DV $-1.5 \mathrm{~mm}$ (Paxinos and Franklin, 2001).

Microdialysis. At $48 \mathrm{~h}$ after the surgical procedure, a CMA/7 microdialysis probe ( $2 \mathrm{~mm}$ membrane length) was inserted into the guide cannula and perfused at a constant flow rate of $1 \mu \mathrm{l} / \mathrm{min}$ with artificial cerebrospinal fluid (aCSF) containing $1 \mu \mathrm{M}$ citalopram, using a microperfusion pump (Harvard Apparatus, Holliston, MA). After a 2-h stabilization period, five microdialysis samples (fractions 1-5) were collected every $10 \mathrm{~min}$ for estimation of basal extracellular 5-HT levels. Mice were then individually placed in a transparent 21 glass cylinder $(19 \mathrm{~cm}$ tall) filled with water at room temperature $\left(25 \pm 2{ }^{\circ} \mathrm{C}\right)$ to a depth of $13 \mathrm{~cm}$. The mice were subjected to $10 \mathrm{~min}$ forced swim stress with concurrent collection of the microdialysis samples (fraction 6). Following the swim stress, three more microdialysate samples were collected (fractions 7-9). At the end of the microdialysis experiment, animals were euthanized and their brains were removed for histological verification of correct probe placement. Only animals with correct probe placement into the right PFC were included in the study.

HPLC. All equipment and materials for the HPLC analysis were obtained from ESA (ESA, Chelmsford, MA). PFC microdialysis samples were analyzed using an HPLC coupled with an electrochemical detector. The mobile phase consisted of a mixture of acetonitrile, phosphate buffer, and an ion-pairing agent. The mobile phase was delivered by a pump (Model 582, Solvent Delivery Module) at a flow rate of $0.25 \mathrm{ml} / \mathrm{min}$ through an $\mathrm{MD}-150$ narrowbore column. 5-HT was detected using a coulometric detector (Coulochem III) coupled to a single-channel enhanced amperometric cell (Model 5041). The potential applied to the electrode was $+150 \mathrm{mV}$; under these conditions, the limit of detection for 
5-HT was approximately 2-3 fmol/sample. Data were analyzed using a computer-assisted software system. For microdialysis data, basal 5-HT levels were defined as the average level of the first five samples following stabilization.

\section{Statistical Analyses}

Statistical analyses were conducted using GraphPad Prism version 4.01 for Windows software (San Diego, CA). The effect of genotype was analyzed using unpaired two-tailed $t$-tests, analysis of variance (ANOVA), or repeated-measures ANOVA, followed by Newman-Keuls post hoc tests where appropriate. Specifically, open field activity and $\mathrm{SIH}$ temperature readings were analyzed by a two-way ANOVA (genotype $\times$ time) with repeated measures for the factor of time. Extracellular levels of 5-HT in microdialysis samples collected every $10 \mathrm{~min}$ were analyzed by one- and two-way ANOVA, with repeated measures for the factor of time. Values in graphs are represented as mean \pm SEM. Sample sizes are indicated in figure legends and results were considered statistically significant if $p<0.05$.

\section{RESULTS}

\section{Generation of MCHR1 Knockout Mice}

The entire coding sequence for MCHR1, consisting of two exons, was targeted and replaced with a neomycin phosphotransferase $\left(\right.$ neo $^{\mathrm{R}}$ ) cassette (Figure 1a). Blastocyst injections of targeted ES cells resulted in chimeric mice, which were further bred with $\mathrm{C} 57 \mathrm{Bl} / 6$ mice. Heterozygote matings produced homozygous wild-type, homozygous mutant, and heterozygous mice in the expected Mendelian ratios. The genetic inactivation of MCHR1 did not impact embryonic viability and the animals appeared grossly normal. Genomic DNA analyzed from tail biopsies confirmed genotypes (Figure 1b) and RT-PCR analysis verified that the null mutation resulted in the absence of MCHR1 mRNA in adult mutant animals (Figure 1c).

\section{MCHR1 Knockout Mice Display Reduced Anxiety-Like Behavior}

Open field activity. Knockout and wild-type mice were tested in the open field, a paradigm of exploratory behavior in a novel environment, and the results are presented in Figure 2. MCHR1 knockout animals spent a significantly greater fraction of time in the central portion of the novel open field. There was a significant effect of genotype $(p<0.005)$ and time $(p<0.05)$ when the data were analyzed in time intervals, but there were no significant genotype $\times$ time interactions (Figure 2a). When the data were collapsed across the 15-min testing period, there was a significant effect of genotype on the distance covered in the central portion of the open field ( $p<0.05$; Figure $2 b)$ as well as the $\%$ activity in the central portion of the open field (data not shown). The greater time spent and distance covered in the center was not a result of increased ambulation, as there were no significant genotypic differences in overall locomotion, as measured by total distance covered during the testing period (Figure $2 \mathrm{c}$ ) and average speed (data not shown).
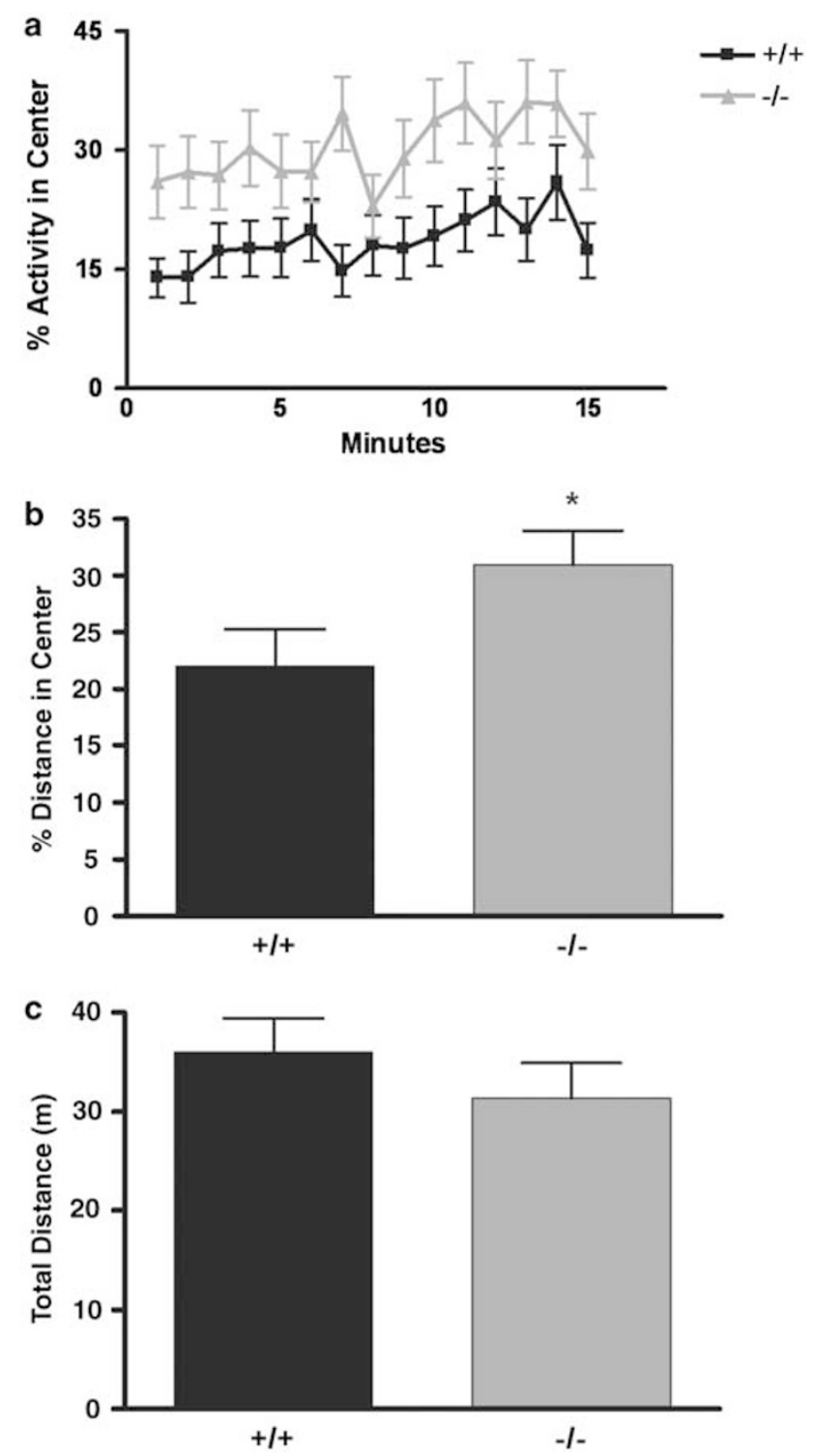

Figure $2 \mathrm{MCHRI}$ knockout mice show reduced anxiety-like behavior in a novel open field test. MCHRI knockout $(-/-)$ and wild-type $(+/+)$ mice were allowed to explore freely an open field for a period of $15 \mathrm{~min}$. (a) MCHRI knockout mice spent a significantly greater fraction of time in the central portion of the open field during the 15-min exposure, indicative of reduced anxiety-like behavior in these mice. When analyzed in time-bin intervals, using a two-way ANOVA with time as the repeated measure, there was a significant effect of genotype $(* * p<0.005)$ and time $(* p<0.05)$ but no genotype $\times$ time interaction $(p=0.85)$. (b) When $\%$ distance covered in the center is examined, collapsed across the 15-min test session, there is a significant effect of genotype (*p<0.05), as assessed by an unpaired $t$-test. (c) There were no significant effects of genotype on the total distance covered by each animal during the trial. Data are presented as mean $( \pm$ SEM) and $n=25-35$ per genotype.

Elevated plus maze. In order to further explore the absence of functional MCHR1 as it relates to anxiety, a test based on the natural aversion of rodents to open or unprotected areas was conducted: the elevated plus maze. Knockout mice spent significantly more time exploring the open arms of the maze $(p<0.01)$ (Figure $3 \mathrm{a})$. The $\%$ of entries into the open arms was also greater for MCHR1 knockout animals 

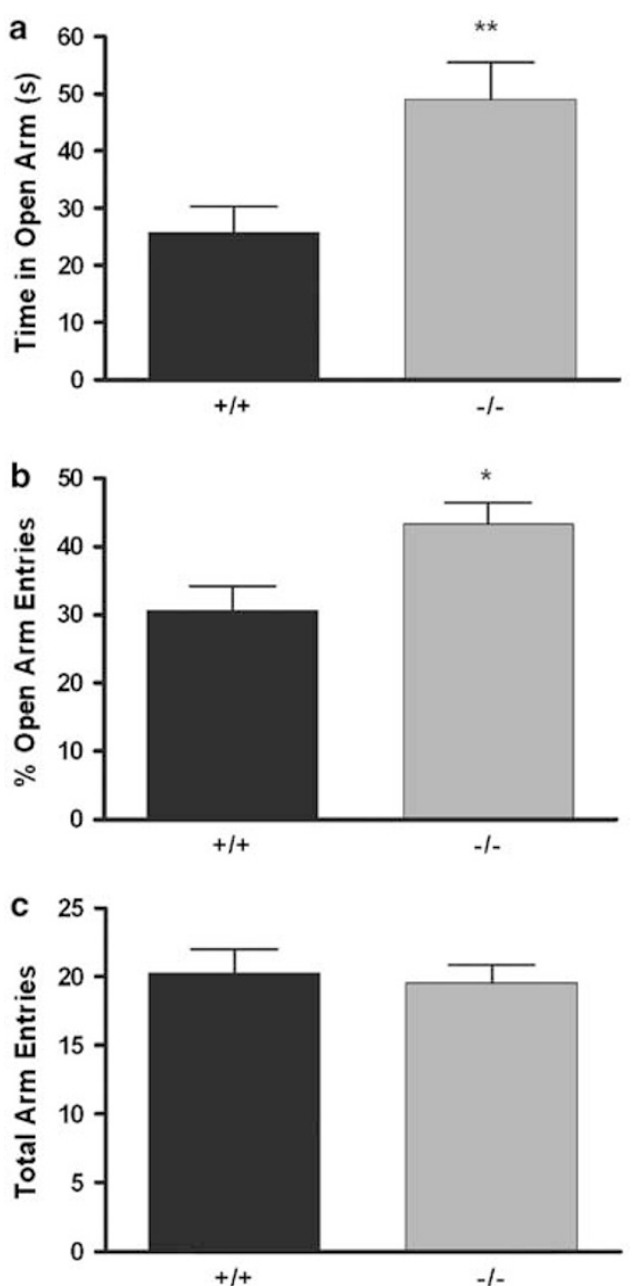

Figure $3 \mathrm{MCHRI}$ knockout mice show reduced anxiety-like behavior on the elevated plus maze. MCHRI knockout $(-/-)$ and wild-type $(+/+)$ mice were subjected to the elevated plus maze for a period of $5 \mathrm{~min}$. (a) MCHRI knockout mice spent a significantly greater amount of time exploring the aversive open arms of the maze (** $<<0.01$ ), and (b) MCHRI knockout mice displayed a greater \% of open arm entries $(* p<0.05)$. (c) No significant differences were detected in total arm entries between MCHRI knockout and wild-type mice, indicative of no differences in locomotor activity. All data were analyzed using an unpaired $t$-test and are presented as mean $( \pm$ SEM $) ; n=11$ per genotype.

$(p<0.05)$ (Figure 3b). There were no overall differences in activity between genotypes, as measured by the total number of arm entries (Figure 3c).

Stress-induced hyperthermia. In mice, the stress-induced hyperthermia procedure has been used to measure antistress or anxiolytic effects of psychoactive drugs. Because the end point being monitored is independent of locomotion, this test is a necessary addition to the standard battery of paradigms used to probe for anxiety-related behaviors. We examined the effects of handling stress-induced increases in core body temperature in knockout and wild-type mice. We found that the basal resting temperature of the MCHR1 knockout mice was significantly higher than that of controls $(p<0.003)$, but was not increased in response to handling stress. In contrast, a significant increase in body

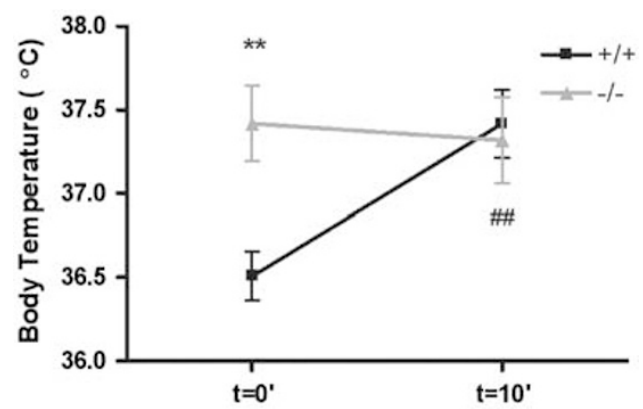

Figure $4 \mathrm{MCHRI}$ knockout mice exhibit higher basal body temperature and are protected against stress-induced hyperthermia. Basal body temperatures were measured in MCHRI knockout $(-/-)$ and wild-type $(+/+)$ mice followed by a second reading 10 min later. A two-way ANOVA with time as the repeated measure indicated a significant effect of time $(* p<0.05)$ as well as a significant genotype $\times$ time interaction $(* * p<0.005)$. Knockout mice exhibit a higher basal body core temperature as compared to wild-type controls and differences were assessed by t-tests: $36.5^{\circ} \mathrm{C} \pm 0.15$ for wild-type and $37.4^{\circ} \mathrm{C} \pm 0.23$ for knockout mice (** $p<0.003)$. At 10 min following handling stress, wild-type, but not knockout, mice responded to the stress with a significant increase in core body temperature: $\Delta T=+0.91^{\circ} \mathrm{C} \pm 0.25$ for wild-type and $-0.10^{\circ} \mathrm{C} \pm 0.35$ for knockout mice. Data are presented as mean $( \pm \mathrm{SEM})$ and $n=11$ per genotype.

temperature following handling stress was observed in wild-type control animals $(p<0.05)$ (Figure 4$)$.

Social interaction. It has been suggested that increased social contact is correlated with anxiolytic-like behavior (File and Hyde, 1978). We examined the behavior of MCHR1 knockout and wild-type mice in a social interaction test in a novel environment. During a 10 -min test period, knockout mice exhibited increased time spent per contact with an intruder-interactor mouse $(p<0.05)$ (Figure 5), when compared with wild-type controls. Contact is defined as sniffing, grooming, mounting, and following behaviors and has been presented in an aggregate manner. MCHR1 knockout mice did not show increased signs of aggressive behavior in this test (data not shown).

\section{MCHR1 Knockout Mice have Altered Serotonin Neurotransmission in the Prefrontal Cortex}

A great body of experimental and clinical evidence implicates central 5-HT transmission in the control of mood and anxiety. In vivo microdialysis, in freely moving mice, was used to assess whether MCHR1 knockout mice had different basal 5-HT levels in the PFC, a region of the brain tightly associated with the regulation of emotion and cognition. Dialysate concentrations of a neurotransmitter can provide an estimate of extracellular concentrations. We found that MCHR1 knockout mice have significantly lower extracellular levels of 5-HT in the PFC, as compared to wildtype animals $(9.53 \pm 0.24 \mathrm{fmol} / 10 \mu \mathrm{l}$ sample for wild type $v s$ $6.91 \pm 0.36 \mathrm{fmol} / 10 \mu \mathrm{l}$ sample for knockout; $p<0.0005)$ (Figure 6a). This effect appears to be specific to 5-HT, since no significant differences in extracellular dopamine (DA) and norepinephrine (NE) levels were detected in MCHR1 knockout mice (data not shown). An acute forced swim stress of $10 \mathrm{~min}$ duration caused a marked and 


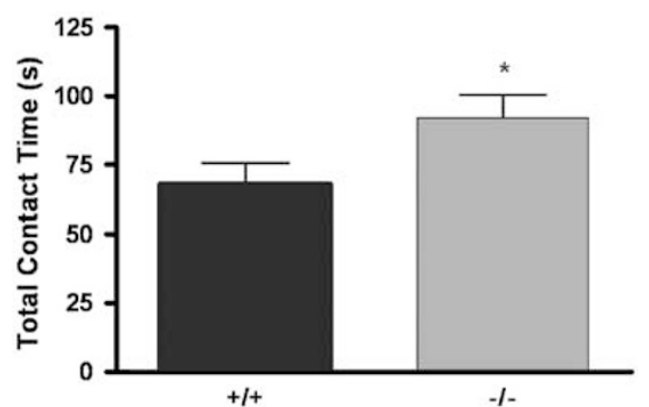

Figure $5 \mathrm{MCHRI}$ knockout mice spent a greater amount of time engaged in social contact. MCHRI knockout mice $(-/-)$, when compared to wild-type mice $(+/+)$, spent a significantly greater amount of total contact time with a novel intruder-interactor mouse in a novel test environment, during a 10-min trial period $(* p<0.05)$, as assessed by an unpaired $t$-test, indicative of reduced fear and anxiety in the face of novelty. Contact is defined as sniffing, following, mounting, and grooming behavior. Data are presented as mean $( \pm$ SEM $)$ and $n=15$ per genotype.

significant increase in 5-HT efflux from the PFC of wildtype mice $(p<0.005)$, while no significant effects were detected in knockout animals (Figure $6 \mathrm{~b}$ ).

\section{DISCUSSION}

Recent studies in rodents have provided intriguing evidence about the involvement of $\mathrm{MCH}$ in the mediation of emotional processes, but its exact role remains to be elucidated. Here we report the generation and behavioral analysis of mice carrying a null mutation of the MCHR1, the only functional $\mathrm{MCH}$ receptor present in mice. The absence of genomic DNA and mRNA was confirmed by PCR-based genotyping and RT-PCR, respectively. While the animals appear grossly normal, we present experimental evidence that genetic inactivation of MCHR1 in mice results in a reduction in anxiety-like behaviors and in changes in serotonergic transmission in the PFC.

A behavioral characterization of the $\mathrm{MCH}$ receptor knockout mouse is a critical step in exploring $\mathrm{MCH}-$ dependent signaling in anxiety-related behaviors. Recruitment of the MCH system in the modulation of anxiety-like behavior is anatomically consistent with the widespread innervation by $\mathrm{MCH}$-immunoreactive fibers of brain areas involved in the modulation of mood and affect (Zamir et al, 1986; Saito et al, 2001). While other groups have shown MCHR1 knockout mice to have altered nutritional homeostasis and energy expenditure (Chen et al, 2002; Marsh et al, 2002), changes in autonomic regulation (Astrand et al, 2004), reduced bone mass (Bohlooly et al, 2004), and supersensitive mesolimbic DA transmission (Smith et al, 2005), our study is the first to demonstrate reduced anxietylike responses in these mice. We show that MCHR1 knockout mice display anxiolytic-like behavior in four different behavioral paradigms that are widely used to assess such responses in rodents.

We observed enhanced exploration of the unprotected central portion of a novel open field and reduced thigmotaxis, behaviors most often correlated with reduced anxiety levels (Treit and Fundytus, 1988; Simon et al, 1994).
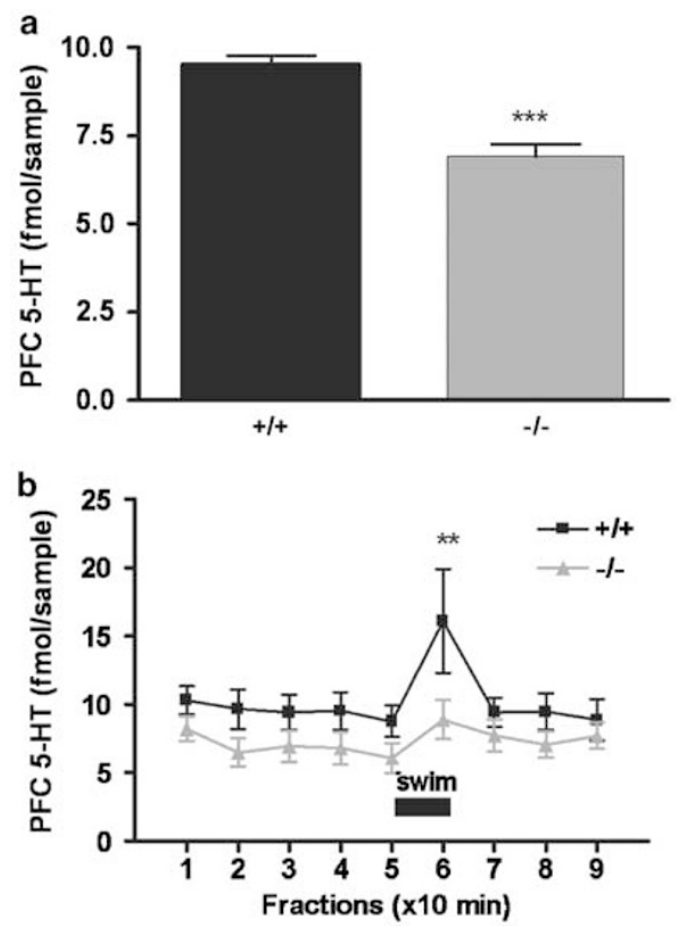

Figure 6 MCHRI knockout mice have reduced extracellular 5-HT levels in the PFC. Basal extracellular 5-HT levels and the effect of a 10-min forced swim on 5-HT efflux in the PFC of knockout $(-/-)$ and wild-type animals $(+/+)$, as assessed by in vivo microdialysis followed by HPLC analysis, are shown. (a) MCHRI knockout mice have significantly lower basal extracellular levels of $5-\mathrm{HT}$ in the PFC: $9.52 \pm 0.24 \mathrm{fmol}$ for wild-type vs $6.91 \pm 0.36 \mathrm{fmol}$ for knockout mice. Basal levels of PFC 5-HT were calculated by averaging the first five microdialysis samples (collected every $10 \mathrm{~min}$ ), and values are expressed as mean ( \pm SEM) fmol of 5-HT in a $10 \mu \mid$ microdialysis sample. A t-test analysis indicated significant differences between the weighted means of baseline samples between knockout and wild-type animals (**** $p<0.0005 ; n=9$ per genotype). (b) Effect of forced swim stress on PFC 5-HT levels. Forced swim caused a significant increase in 5-HT release from the PFC of wild-type but not knockout mice. Oneway ANOVA with time as the repeated measure indicated a significant change in 5-HT efflux over time in the wild-type group $(* * 2<0.005)$, but not in the knockout group. Post hoc comparisons of individual samples revealed a significantly higher 5-HT efflux following the forced swim only in the wild-type animals. Two-way ANOVA with time as the repeated measure indicated a significant effect of time $(* * * *<0.0005)$ but not of genotype $(p<0.08)$, and there was no genotype $\times$ time interaction.

In the elevated plus maze, knockout mice spent a greater amount of time exploring the aversive open arms of the maze, as compared to wild-type controls, consistent with a reduced anxiety-like response in this test. It is important to note that decreases in measures of anxiety in the open field and the elevated plus maze did not result from increased locomotor activity, since no significant differences in the total distance traveled during the open field session and the number of total arm entries were observed between knockout and wild-type animals on these tests, respectively.

MCHR1 knockout mice also displayed anxiolytic-like behavior when tested in a novel-environment social interaction test. Knockout mice spent a significantly greater amount of time investigating an intruder male mouse, when compared to wild-type controls. No signs of increased aggression were detected, further suggesting reduced fear 
and anxiety in the face of novelty. An anxiolytic-like response was also observed in a model of stress-induced hyperthermia. In this paradigm, MCHR1 knockout mice appeared to be protected against handling stress-induced increases in core body temperature, as compared to wildtype controls. We observe here, however, that MCHR1 knockout mice have basal body temperature $1.0^{\circ} \mathrm{C}$ higher than wild-type controls (also observed by Astrand et al (2004), but only during the dark phase). While the lack of effect of stress-induced hyperthermia in knockout mice may have been due to their higher basal body temperature, other groups have shown stress-induced hyperthermia to exceed a $2{ }^{\circ} \mathrm{C}$ change in body temperature in mice with similar C57Bl/ 6 genetic backgrounds (Butterweck et al, 2003). Therefore, a physiological limit may not have been reached in the MCHR1 knockouts, thus further suggesting an anxiolyticlike phenotype in these mutant mice.

The data obtained studying this MCHR1 knockout mouse model are consistent with published findings that pharmacological inactivation of $\mathrm{MCHR} 1$ receptors results in a reduction in measures of anxiety. Reduced anxiety-like behavior following acute treatment with SNAP-7941 (Borowsky et al, 2002) and ATC0065/0175 (Chaki et al, 2005) was observed in rats and mice using a variety of behavioral paradigms, much like the present study. Modulation of anxiety-like behavioral responses has also been observed following i.c.v. injections of the MCH ligand (Gonzalez et al, 1996; Monzon and De Barioglio, 1999; Kela et al, 2003).

Both the expression of MCHR1 and the innervation of $\mathrm{MCH}$-containing fibers have been described in the rodent dorsal raphé (Hervieu et al, 2000; Saito et al, 2001), the region of the brain where the cell bodies for serotonergic neurons are located. It has been known for several decades that serotonergic transmission plays a key role in the modulation of mood, anxiety and stress (extensively reviewed in Gordon and Hen, 2004). Specific changes in the 5-HT system of patients with affective disorders have been found primarily in the PFC, a brain region tightly associated with the control of emotion and cognition (Stockmeier, 1997; Dean et al, 1999; Miller, 1999). Moreover, 5-HT transmission in the PFC has been implicated specifically in modulating anxiety and fear. For example, 5-HT efflux is increased in the PFC in the elevated plus maze (Rex et al, 1993), a test of anxiety, as well as during conditioned fear (Hashimoto et al, 1999). Acute stressful events such as forced swim can increase 5-HT transmission in the brains of freely moving mice (Kirby et al, 1997; Yoshitake et al, 2004). Further existence of a link between fear/anxiety processes and 5-HT is demonstrated by the fact that several clinically used antianxiety medications (eg SSRIs, 5- $\mathrm{HT}_{1 \mathrm{~A}}$ agonists) are believed to exert their therapeutic effects through a selective modulation of serotonergic neurotransmission. To address whether the absence of functional MCHR1 receptors alters 5-HT transmission in the PFC, we performed in vivo microdialysis studies in freely moving mice. We found that MCHR1 knockout mice have reduced basal extracellular 5HT levels in the PFC, but no differences in DA and NE, and that while acute swim stress increased 5-HT efflux in the PFC of wild-type mice, no significant effects were detected in knockout animals. This suggests that genetic inactivation of MCHR1 blocks the neurochemical effects of acute stress exposure in a brain area largely implicated in behavioral responses to fear and anxiety.

Since several lines of evidence indicate that altered serotonergic transmission in the PFC can modulate fearand anxiety-related behaviors, one could speculate that the lower basal 5-HT levels and the blunted 5-HT response following acute stress may underlie the decrease in anxiety states in MCHR1 knockout mice. In this regard, it is interesting to note that $5 \mathrm{HT}_{1 \mathrm{~A}}$ receptor knockout mice have increased 5-HT levels in forebrain areas, including the PFC (Parsons et al, 2001), and display concomitant anxious behavior (Heisler et al, 1998; Parks et al, 1998; Ramboz et al, 1998). This suggests that disinhibition of 5-HT neurotransmission could lead to increases in anxiety-like behaviors. On the other hand, our data show that genetic inactivation of $\mathrm{MCHR} 1$ reduces $\mathrm{PFC}$ 5-HT transmission, possibly contributing to the observed anxiolytic-like phenotype. Several possibilities could explain the reduced 5 -HT transmission in the PFC of MCHR1 knockout mice. For example, MCH-mediated signaling through MCHR1 may usually provide a tonic excitatory drive of raphé serotonergic neurons. Thus, in the knockout mice, the lack of functional MCHR1 receptors normally expressed in the raphé (Hervieu et al, 2000; Saito et al, 2001) may lead to reduced 5-HT levels in projection fields like the PFC and ultimately modulate anxiety-like behavior and response to acute stress. Alternatively, the lack of functional MCHR1 could lead to changes in $5 \mathrm{HT}_{1 \mathrm{~A}}$ inhibitory autoreceptors or in 5-HT transporter expression/activity. In addition, one explanation that must also be considered is that $\mathrm{MCH}$ signaling through its cognate receptor may act in a trophic manner to promote development of the serotonergic circuitry necessary for normal anxiety-like behaviors. However, in light of studies concluding that acute administration of a specific MCHR1 antagonist reduces anxiety-like behavior (Borowsky et al, 2002; Chaki et al, 2005), the trophic hypothesis of $\mathrm{MCH}$ signaling-induced effects on serotonergic transmission cannot solely explain the observed reduction in anxietylike behaviors.

To complement the studies presented here and to further examine effects of MCHR1 downregulation on neurochemistry and associated behaviors, studies utilizing conditional knockouts and selective MCHR1 receptor antagonists are warranted. In conclusion, our findings show that genetic inactivation of the MCHR1 results both in reduced anxietylike behavior across a battery of tests in mice and in altered prefrontal cortical serotonergic transmission. These data shed light on the role of the $\mathrm{MCH}$ signaling system in the regulation of fear and anxiety and provide further evidence that pharmacological manipulation of this system may represent an alternative strategy for the clinical management of anxiety disorders.

\section{ACKNOWLEDGEMENTS}

We thank Dr Chris Fibiger for critically reviewing the manuscript and Dr Russell G Phillips for assistance with the statistical analyses of the data. 


\section{REFERENCES}

Astrand A, Bohlooly YM, Larsdotter S, Mahlapuu M, Andersen H, Tornell J et al (2004). Mice lacking melanin-concentrating hormone receptor 1 demonstrate increased heart rate associated with altered autonomic activity. Am J Physiol Regul Integr Comp Physiol 287: R749-R758.

Bittencourt JC, Frigo L, Rissman RA, Casatti CA, Nahon JL, Bauer JA (1998). The distribution of melanin-concentrating hormone in the monkey brain (Cebus apella). Brain Res 804: 140-143.

Bittencourt JC, Presse F, Arias C, Peto C, Vaughan J, Nahon JL et al (1992). The melanin-concentrating hormone system of the rat brain: an immuno- and hybridization histochemical characterization. J Comp Neurol 319: 218-245.

Bohlooly YM, Mahlapuu M, Andersen H, Astrand A, Hjorth S, Svensson L et al (2004). Osteoporosis in MCHR1-deficient mice. Biochem Biophys Res Commun 318: 964-969.

Borowsky B, Durkin MM, Ogozalek K, Marzabadi MR, DeLeon J, Lagu B et al (2002). Antidepressant, anxiolytic and anorectic effects of a melanin-concentrating hormone-1 receptor antagonist. Nat Med 8: 825-830.

Bouwknecht JA, Paylor R (2002). Behavioral and physiological mouse assays for anxiety: a survey in nine mouse strains. Behav Brain Res 136: 489-501.

Butterweck V, Prinz S, Schwaninger M (2003). The role of interleukin-6 in stress-induced hyperthermia and emotional behaviour in mice. Behav Brain Res 144: 49-56.

Chaki S, Funakoshi T, Hirota-Okuno S, Nishiguchi M, Shimazaki $\mathrm{T}$, Iijima $\mathrm{M}$ et al (2005). Anxiolytic- and antidepressant-like profile of ATC0065 and ATC0175: nonpeptidic and orally active melanin-concentrating hormone receptor 1 antagonists. J Pharmacol Exp Ther 313: 831-839.

Chen Y, Hu C, Hsu CK, Zhang Q, Bi C, Asnicar M et al (2002). Targeted disruption of the melanin-concentrating hormone receptor-1 results in hyperphagia and resistance to diet-induced obesity. Endocrinology 143: 2469-2477.

Dean B, Hussain T, Hayes W, Scarr E, Kitsoulis S, Hill C et al (1999). Changes in serotonin $2 A$ and GABA(A) receptors in schizophrenia: studies on the human dorsolateral prefrontal cortex. J Neurochem 72: 1593-1599.

File SE, Hyde JR (1978). Can social interaction be used to measure anxiety? Br J Pharmacol 62: 19-24.

Gonzalez MI, Vaziri S, Wilson CA (1996). Behavioral effects of alpha-MSH and MCH after central administration in the female rat. Peptides 17: 171-177.

Gordon JA, Hen R (2004). The serotonergic system and anxiety. Neuromol Med 5: 27-40.

Griffond B, Baker BI (2002). Cell and molecular cell biology of melanin-concentrating hormone. Int Rev Cytol 213: 233-277.

Hashimoto S, Inoue T, Koyama T (1999). Effects of conditioned fear stress on serotonin neurotransmission and freezing behavior in rats. Eur J Pharmacol 378: 23-30.

Heisler LK, Chu HM, Brennan TJ, Danao JA, Bajwa P, Parsons LH et al (1998). Elevated anxiety and antidepressant-like responses in serotonin 5-HT1A receptor mutant mice. Proc Natl Acad Sci USA 95: 15049-15054.

Hervieu GJ, Cluderay JE, Harrison D, Meakin J, Maycox P, Nasir S et al (2000). The distribution of the mRNA and protein products of the melanin-concentrating hormone $(\mathrm{MCH})$ receptor gene, slc-1, in the central nervous system of the rat. Eur J Neurosci 12: 1194-1216.

Holmes A, Lit Q, Murphy DL, Gold E, Crawley JN (2003). Abnormal anxiety-related behavior in serotonin transporter null mutant mice: the influence of genetic background. Genes Brain Behav 2: 365-380.

Kawauchi H, Kawazoe I, Tsubokawa M, Kishida M, Baker BI (1983). Characterization of melanin-concentrating hormone in chum salmon pituitaries. Nature 305: 321-323.
Kela J, Salmi P, Rimondini-Giorgini R, Heilig M, Wahlestedt C (2003). Behavioural analysis of melanin-concentrating hormone in rats: evidence for orexigenic and anxiolytic properties. Regul Pept 114: 109-114.

Kirby LG, Chou-Green JM, Davis K, Lucki I (1997). The effects of different stressors on extracellular 5-hydroxytryptamine and 5-hydroxyindoleacetic acid. Brain Res 760: 218-230.

Lister RG (1987). The use of a plus-maze to measure anxiety in the mouse. Psychopharmacology (Berl) 92: 180-185.

Marsh DJ, Weingarth DT, Novi DE, Chen HY, Trumbauer ME, Chen AS et al (2002). Melanin-concentrating hormone 1 receptor-deficient mice are lean, hyperactive, and hyperphagic and have altered metabolism. Proc Natl Acad Sci USA 99: 3240-3245.

Miller EK (1999). The prefrontal cortex: complex neural properties for complex behavior. Neuron 22: 15-17.

Miyakawa T, Leiter LM, Gerber DJ, Gainetdinov RR, Sotnikova TD, Zeng $\mathrm{H}$ et al (2003). Conditional calcineurin knockout mice exhibit multiple abnormal behaviors related to schizophrenia. Proc Natl Acad Sci USA 100: 8987-8992.

Monzon ME, De Barioglio SR (1999). Response to novelty after i.c.v. injection of melanin-concentrating hormone $(\mathrm{MCH})$ in rats. Physiol Behav 67: 813-817.

Monzon ME, Varas MM, De Barioglio SR (2001). Anxiogenesis induced by nitric oxide synthase inhibition and anxiolytic effect of melanin-concentrating hormone $(\mathrm{MCH})$ in rat brain. Peptides 22: 1043-1047.

Monzon ME, de Souza MM, Izquierdo LA, Izquierdo I, Barros DM, de Barioglio SR (1999). Melanin-concentrating hormone (MCH) modifies memory retention in rats. Peptides 20: 1517-1519.

Parks CL, Robinson PS, Sibille E, Shenk T, Toth M (1998). Increased anxiety of mice lacking the serotonin1A receptor. Proc Natl Acad Sci USA 95: 10734-10739.

Parsons LH, Kerr TM, Tecott LH (2001). 5-HT(1A) receptor mutant mice exhibit enhanced tonic, stress-induced and fluoxetine-induced serotonergic neurotransmission. J Neurochem 77: 607-617.

Paxinos G, Franklin KBJ (2001). The Mouse Brain in Stereotaxic Coordinates 2nd edn. Academic Press: New York.

Qu D, Ludwig DS, Gammeltoft S, Piper M, Pelleymounter MA, Cullen MJ et al (1996). A role for melanin-concentrating hormone in the central regulation of feeding behaviour. Nature 380: $243-247$.

Ramboz S, Oosting R, Amara DA, Kung HF, Blier P, Mendelsohn M et al (1998). Serotonin receptor 1A knockout: an animal model of anxiety-related disorder. Proc Natl Acad Sci USA 95: 14476-14481.

Rex A, Marsden CA, Fink H (1993). Effect of diazepam on cortical 5 -HT release and behaviour in the guinea-pig on exposure to the elevated plus maze. Psychopharmacology (Berl) 110: 490-496.

Saito Y, Cheng M, Leslie FM, Civelli O (2001). Expression of the melanin-concentrating hormone $(\mathrm{MCH})$ receptor mRNA in the rat brain. J Comp Neurol 435: 26-40.

Shimada M, Tritos NA, Lowell BB, Flier JS, Maratos-Flier E (1998). Mice lacking melanin-concentrating hormone are hypophagic and lean. Nature 396: 670-674.

Simon P, Dupuis R, Costentin J (1994). Thigmotaxis as an index of anxiety in mice. Influence of dopaminergic transmissions. Behav Brain Res 61: 59-64.

Smith DG, Tzavara ET, Shaw J, Luecke S, Wade M, Davis R et al (2005). Mesolimbic dopamine super-sensitivity in melaninconcentrating hormone-1 receptor-deficient mice. J Neurosci 25: 914-922.

Stockmeier CA (1997). Neurobiology of serotonin in depression and suicide. Ann NY Acad Sci 836: 220-232.

Tan CP, Sano H, Iwaasa H, Pan J, Sailer AW, Hreniuk DL et al (2002). Melanin-concentrating hormone receptor subtypes 1 and 2: species-specific gene expression. Genomics 79: 785-792. 
Treit D, Fundytus M (1988). Thigmotaxis as a test for anxiolytic activity in rats. Pharmacol Biochem Behav 31: 959-962.

Van der Heyden JA, Zethof TJ, Olivier B (1997). Stress-induced hyperthermia in singly housed mice. Physiol Behav 62: 463-470.

Yoshitake T, Wang FH, Kuteeva E, Holmberg K, Yamaguchi M, Crawley JN et al (2004). Enhanced hippocampal noradrenaline and serotonin release in galanin-overexpressing mice after repeated forced swimming test. Proc Natl Acad Sci USA 101: 354-359.

Zamir N, Skofitsch G, Jacobowitz DM (1986). Distribution of immunoreactive melanin-concentrating hormone in the central nervous system of the rat. Brain Res 373: 240-245. 